\title{
¿Está justificada la extensión de la figura del indefinido no fijo que realiza a los trabajadores de sociedades mercantiles públicas la STS de 18 de junio de 2020 (Ro. 2811/2018, Sala de los Social)?
}

\author{
Is it justified the extension of the indefinite non-worker figure \\ to workers of public trading companies done by the Sentence \\ of the Spanish Supreme Court of 18th June 2020 \\ (Appeal number 2811/2018, Labour Chamber)?
}

Francisco Javier Arrieta Idiakez*

Profesor Titular de Derecho del Trabajo y Seguridad Social

Universidad de Deusto

ORCID ID: 0000-0003-4696-6356

Recibido: 04/09/2020

Aceptado: 02/10/2020

doi: https://doi.org/10.20318/labos.2020.5776

Resumen: $\quad$ El objetivo de este trabajo es comentar la STS de 18 de junio de 2020 (Ro. $2811 / 2018$, Sala de los Social) para criticar la extensión de la figura del indefinido no fijo a las sociedades mercantiles públicas. A tal efecto, tras resaltar el interés de la sentencia, se realizará una descripción de los hechos que dan lugar al litigio, se describirá la problemática planteada, se profundizará en la resolución y los Fundamentos de Derecho que la motivan, se centrará la atención en el Voto Particular existente, y, finalmente, se realizará una valoración personal en la que se considerarán aspectos que de haber sido considerados hubieran supuesto la no extensión de la figura del indefinido no fijo a las sociedades mercantiles públicas.

Palabras clave: sociedades mercantiles públicas, trabajadores fijos, trabajadores indefinidos no fijos, sector público, empleo público.

Abstract: $\quad$ The purpose of this paper is to discuss the Sentence of the Spanish Supreme Court of 18th June 2020 (Appeal number 2811/2018, Labour Chamber) in order to criticise the extension of the indefinite non-worker figure to public trading companies. To that end, and after highlighting the interest of the Sentence, we will describe the facts of the dispute, we will describe the conflict, we will delve into the resolution and the legal grounds, we will pay attention to the dissenting vote and, lastly, we will carry out a personal assessment by means of which we will consider some key aspects that would have entailed the nonextension of the indefinite non-worker figure to public trading companies.

Keywords: $\quad$ public trading companies, fixed workers, indefinite non-fixed workers, public sector, public employment. 


\section{Interés de la sentencia en cuestión}

El interés de la sentencia objeto de estudio radica en que después de muchos vaivenes, se sienta jurisprudencia respecto a la extensión de la figura del indefinido no fijo a las sociedades mercantiles públicas, a través de la resolución de un recurso de casación en unificación de doctrina interpuesto por AENA S.A. En cualquier caso, la decisión adoptada por el TS de proceder a dicha extensión resulta polémica, como lo demuestra el Voto Particular con el que cuenta la sentencia, en el que se critica dicha extensión y se aboga por otorgar la naturaleza de trabajadores fijos a quienes han sido previamente contratados en fraude de ley en las sociedades mercantiles públicas. Además, no resulta menos significativo que no se haya tomado en consideración la recientísima STJUE de 19 de marzo de 2020 (asuntos acumulados C-103/18 y C-429/18, Domingo Sánchez Ruiz y otros), ni lo establecido en la Disposición Adicional 34a de la Ley 3/2017, de 27 de junio, de Presupuestos Generales del Estado para $2017^{1}$.

\section{Descripción de los hechos}

Dos trabajadoras por cuenta ajena que prestan sus servicios para AENA S.A., en el centro de trabajo del aeropuerto de Barcelona-El Prat, con la categoría profesional de IC-17-Apoyo Atención a Pasajeros, Usuarios y Clientes, tienen una antigüedad desde noviembre de 2010. En concreto, desde dicha fecha al 31 de mayo de 2015 trabajaron para AENA S.A. con distintos contratos de interinidad encadenados entre sí. Además, de manera excepcional, una de las trabajadoras prestó sus servicios bajo la modalidad del contrato de relevo entre el 1 de octubre de 2013 y el 31 de agosto de 2014 .

Sin embargo, a partir del 31 de mayo de 2015 se da la circunstancia de que ambas trabajadoras son contratadas con un contrato de trabajo de obra o servicio determinado, con efectos a partir del 1 de junio de 2015 y hasta la actualidad.

Del mismo modo, a pesar de que el 8 de enero de 2015 AENA S.A. suscribiera un contrato con la mercantil Ferroser Infraestructuras S.A. con el objetivo de proceder al cambio de denominación de puertas de embarque de la terminal T-2, y de que dicho cambio se produjera, las trabajadoras continuaron desarrollando idénticas funciones, a saber, ocuparse indistintamente de las necesidades de atención al público derivadas de dicho cambio de denominación y de las restantes necesidades de los usuarios de la terminal.

Las trabajadoras decidieron, finalmente, demandar a AENA S.A. con el fin de que se reconociera su carácter de trabajadoras fijas de plantilla, después de que el acto de conciliación celebrado el 26 de septiembre de 2016 finalizara con el resultado de "sin efecto", al entender que sus contratos temporales se habían celebrado en fraude de ley.

Como consecuencia de la mencionada demanda, el Juzgado de lo Social no 17 de los de Barcelona dictó sentencia el 28 de septiembre de 2017 (procedimiento no 696/2016), declarando el carácter fijo de las dos trabajadoras con antigüedad desde noviembre de 2010, es decir, desde que comenzaron a prestar sus servicios para AENA S.A.

AENA S.A. recurrió en suplicación, y la Sala de los Social del TSJ de Cataluña dictó sentencia el 5 de abril de 2018 (Ro. 229/2018) confirmando íntegramente la sentencia de instancia.

Finalmente, AENA S.A. interpuso recurso de casación para la unificación de doctrina contra esta última sentencia.

${ }^{1}$ BOE de 28 de junio de 2017, no. 153. 


\section{Problemática planteada}

El F.D. $1^{\circ}$ de la sentencia objeto de estudio expone con claridad la problemática planteada y que constituye el objeto del recurso de casación para la unificación de doctrina interpuesto por AENA S.A. En concreto, la problemática consiste en "determinar si la celebración de contratos en fraude de ley por una sociedad mercantil, encuadrada en el sector público, comporta que se reconozca a los trabajadores afectados la condición de fijos de plantilla o, por el contrario, solo cabe declararlos indefinidos no fijos".

$\mathrm{Al}$ respecto, veamos, a continuación, las posiciones de la sentencia recurrida y de la sentencia de contraste aportada por AENA S.A., así como la argumentación de AENA S.A. para fundamentar su recurso de casación para la unificación de doctrina.

\subsection{Posición de la sentencia recurrida}

Ante esa disyuntiva, la sentencia recurrida se decantaba por la primera opción bajo la argumentación de que AENA S.A. no es una Administración Pública, sino una sociedad mercantil pública sometida a las normas de Derecho privado, tanto en su organización como en su actividad, incluida la contratación. Por consiguiente, concluye que no resulta de aplicación el Real Decreto Legislativo 5/2015, de 30 de octubre, por el que se aprueba el texto refundido de la Ley del Estatuto Básico del Empleado Público (TRLEBEP)², ya que el ámbito de aplicación del mismo se ciñe al personal de las Administraciones Públicas. A la luz de todo ello, en referencia a la figura de los indefinidos no fijos, señala que resulta difícil sostener que los trabajadores de una sociedad de Derecho privado puedan ser calificados como tales, "al ser esta una calificación creada jurisprudencialmente para garantizar la situación de quienes prestan servicios para entidades públicas en un régimen de laboralidad que no se sujeta a una causa legal de temporalidad". Además, trae a colación las palabras del Tribunal Supremo, para matizar que la justificación de la figura del trabajador indefinido no fijo "se halla en la necesidad de preservar los principios que rigen el acceso al ejercicio de una función pública, elemento justificativo que desaparece por completo en el ámbito de las relaciones privadas".

\subsection{Posición de la sentencia de contraste aportada por AENA S.A.}

Por su parte, la sentencia de contraste que aporta AENA S.A. para sostener su recurso de casación para la unificación de doctrina, a saber, la STSJ de Cataluña, de 11 de mayo de 2010 (Ro. 6855/2008, Sala de lo Social), aboga por la segunda opción. En efecto, se reconoce el carácter de indefinido no fijo de un trabajador que prestaba servicios para la Sociedad Mercantil Estatal Radio Nacional de España S.A. (RNE S.A.), principalmente, por los siguientes cuatro motivos:

(a) La consideración de que RNE S.A. presta un servicio público en virtud de lo establecido en la Ley 17/2006, de 5 de junio, de la radio y la televisión de titularidad estatal ${ }^{3}$, y de lo dictaminado por la STSJ de Cataluńa, de 19 de marzo de 2009 (Rº. 7827/2007, Sala de lo Social).

\footnotetext{
${ }^{2}$ BOE de 31 de octubre de 2015, no 261.

${ }^{3}$ BOE de 6 de junio de 2006, no 134.
} 
(b) El hecho de que conforme a la Disposición Adicional 12a de la Ley 6/1997, de 14 de abril, de Organización y Funcionamiento de la Administración General del Estado (LOFAGE) ${ }^{4}$, las sociedades mercantiles estatales no se rijan por el ordenamiento jurídico privado en materia de contratación.

(c) La obligación de subrogación que impone la Disposición Transitoria 2a, apartado $2^{\circ}$, de la Ley 17/2006 a la Corporación RTVE y a las sociedades prestadoras del servicio público, respectivamente, para con la posición jurídica que ostentaba el Ente Público RTVE y las sociedades TVE, S.A., y RNE, S.A., en las relaciones jurídicas, derechos y obligaciones de naturaleza laboral, convencional o extraconvencional, y de Seguridad Social de los trabajadores que se incorporen a las nuevas entidades.

(d) Lo preceptuado por el artículo 15 del Convenio colectivo aplicable a la Sociedad Mercantil Estatal Radio Nacional de Espańa S.A., en tanto en cuanto regula los procedimientos para adquirir la condición de trabajadores fijos de plantilla: oposición, concurso, concurso-oposición o cualquier otro procedimiento de selección objetiva que se determine.

\subsection{Argumentación de AENA S.A. para fundamentar su recurso de casación para la unificación de doctrina}

AENA S.A. denuncia como único motivo de casación para la unificación de doctrina la infracción del artículo 18 de la Ley 3/2017, de 27 de junio, de Presupuestos Generales del Estado para 2017, en relación con los artículos 111.1 y 113 de la Ley 40/2015, de 1 de octubre, de Régimen Jurídico del Sector Público (LRJSP); la Disposición Adicional Primera y el artículo 55 del TRLEBEP; y los artículos 23 y 24 del I Convenio colectivo del Grupo de empresas AENA 5 .

De este modo, a los efectos que aquí interesan, hay que tener en cuenta que el artículo 18 de la Ley 3/2017, en su apartado Uno. f), establece que, respecto a los gastos del personal al servicio del sector público, las sociedades mercantiles públicas forman parte del sector público. Es más, define dichas sociedades como "aquellas en las que la participación, directa o indirecta, en su capital social de las Administraciones y entidades que se enumeran en el mismo precepto sea superior al 50\%. Asimismo, dispone que "en el sector público estatal se considerarán como tales las reguladas en el artículo 111.1 de la LRJSP”. En concreto, conforme a esta última disposición:

"Se entiende por sociedad mercantil estatal aquella sociedad mercantil sobre la que se ejerce control estatal:

a) Bien porque la participación directa, en su capital social de la Administración General del Estado o alguna de las entidades que, conforme a lo dispuesto en el artículo 84, integran el sector público institucional estatal, incluidas las sociedades mercantiles estatales, sea superior al 50 por 100. Para la determinación de este porcentaje, se sumarán las participaciones correspondientes a la Administración General del Estado y a todas las entidades integradas en el sector público institucional estatal, en el caso de que en el capital social participen varias de ellas.

b) Bien porque la sociedad mercantil se encuentre en el supuesto previsto en el artículo 4 de la Ley 24/1988, de 28 de julio, del Mercado de Valores ${ }^{6}$, respecto de la Administración General del Estado o de sus organismos públicos vinculados o dependientes".

${ }^{4}$ BOE de 15 de abril de 1997, no. 90. Ley derogada, con efectos desde el 2 de octubre de 2016, por la Ley 40/2015, de 1 de octubre, de Régimen Jurídico del Sector Público (LRJSP) (BOE de 2 de octubre de 2015, nº. 236), si bien a los efectos aquí señalados se mantiene la excepción relativa a la inaplicación del ordenamiento jurídico privado en materia de contratación (véase el artículo 113 , relativo al régimen jurídico).

${ }^{5}$ BOE de 20 de diciembre de 2011, no. 305.

${ }^{6}$ BOE de 29 de julio de 1988, no 181 . Conforme al artículo 4 de dicha ley, a los efectos de la misma debía estarse a la definición 
Por su parte, el artículo 113 de la LRJSP, relativo al régimen jurídico de las sociedades mercantiles estatales, establece lo siguiente:

"Las sociedades mercantiles estatales se regirán por lo previsto en esta Ley, por lo previsto en la Ley 33/2003, de 3 de noviembre, [de Patrimonio de las Administraciones Públicas (LPAP)'] y por el ordenamiento jurídico privado, salvo en las materias en que le sea de aplicación la normativa presupuestaria, contable, de personal, de control económico-financiero y de contratación. En ningún caso podrán disponer de facultades que impliquen el ejercicio de autoridad pública, sin perjuicio de que excepcionalmente la ley pueda atribuirle el ejercicio de potestades administrativas".

En lo que se refiere a los preceptos del TRLEBEP alegados, por una parte, la Disposición Adicional primera, bajo la rúbrica "Ámbito específico de aplicación”, matiza que:

"Los principios contenidos en los artículos 52, 53, 54, 55 y 59 serán de aplicación en las entidades del sector público estatal, autonómico y local, que no estén incluidas en el artículo 2 del presente Estatuto y que estén definidas así en su normativa específica”.

Y, por otra parte, en íntima conexión con dicha matización, el artículo 55, que versa sobre los "principios rectores" en el acceso al empleo público y adquisición de la relación de servicio, establece lo siguiente:

"1. Todos los ciudadanos tienen derecho al acceso al empleo público de acuerdo con los principios constitucionales de igualdad, mérito y capacidad, y de acuerdo con lo previsto en el presente Estatuto y en el resto del ordenamiento jurídico.

2. Las Administraciones Públicas, entidades y organismos a que se refiere el artículo 2 del presente Estatuto seleccionarán a su personal funcionario y laboral mediante procedimientos en los que se garanticen los principios constitucionales antes expresados, así como los establecidos a continuación:

a) Publicidad de las convocatorias y de sus bases.

b) Transparencia.

c) Imparcialidad y profesionalidad de los miembros de los órganos de selección.

d) Independencia y discrecionalidad técnica en la actuación de los órganos de selección.

e) Adecuación entre el contenido de los procesos selectivos y las funciones o tareas a desarrollar.

f) Agilidad, sin perjuicio de la objetividad, en los procesos de selección."

Por último, respecto al I Convenio colectivo del Grupo de empresas AENA, los artículos 23 y 24 que se alegan como vulnerados se encuadran dentro del Capítulo V del convenio, bajo el título "Provisión de puestos de trabajo, contratación e ingreso y promoción".

En concreto, el artículo 23 se ubica en la Sección 2a, relativa a la "Selección externa", y regula el "Sistema de ingreso". En lo que aquí interesa, debe destacarse que en el apartado 3 se establece que "en cualquier caso se respetarán los principios de igualdad, mérito, capacidad y publicidad".

Por su parte, el artículo 24 se ubica en la Sección $3^{\text {a }}$, relativa a la "Comisión Paritaria de Promoción y Selección y las comisiones de vigilancia y observación (CPPS)”. Del mismo, debe destacarse, para con el litigio objeto de estudio, lo dispuesto en el apartado 1:

de grupo de sociedades establecida en el artículo 42 del Código de Comercio. Debe tenerse en cuenta que a pesar de que dicha norma fue derogada por el Real Decreto Legislativo 4/2015, de 23 de octubre, por el que se aprueba el texto refundido de la Ley del Mercado de Valores (BOE de 24 de octubre de 2015, no 255), la misma viene a establecer exactamente lo mismo en su artículo 5, bajo la rúbrica "Grupo de Sociedades".

${ }^{7}$ BOE de 4 de noviembre de 2003, no. 264. 
"La Comisión Paritaria de Promoción y Selección tiene por objeto garantizar el adecuado control, calidad y homogeneidad de los procesos de selección, para garantizar el cumplimiento de la legislación laboral, del presente Convenio colectivo, así como los principios de igualdad de oportunidades, mérito, capacidad y publicidad".

\section{Resolución y Fundamentos de Derecho que la motivan}

Analizada la disyuntiva plateada, el TS considera que concurren los requisitos de contradicción y, tras aceptar el recurso, entra a conocer del fondo del asunto, teniendo en cuenta que AENA S.A. también es una sociedad mercantil pública; que las trabajadoras demandantes, al igual que sucede con el trabajador demandante de la sentencia de contraste aportada por aquellas, son contratadas en fraude de ley, motivo por el que reclaman su condición de trabajadoras fijas; y que pese a tratarse de sociedades mercantiles distintas en ambos casos la normativa aplicable considera a ambas encuadrables en el sector público estatal.

Ante esta controversia, la sentencia objeto de estudio, de cara a posicionarse a favor de una $\mathrm{u}$ otra postura, y, en función de ello, resolver el litigio planteado, analiza, en los Fundamentos de Derecho $3^{\circ}$ a $8^{\circ}$, diversos aspectos desde la perspectiva tanto legislativa como jurisprudencial, y establece las conclusiones pertinentes. Todo ello puede resumirse como sigue:

(1) Con apoyo en lo dictaminado por la STC 8/2015, de 22 de enero, se concluye que las sociedades mercantiles estatales forman parte del sector público empresarial.

(2) Del articulado del TRLEBEP y, más concretamente, conforme a los artículos 90.3 y 85 , cabe diferenciar, respectivamente, entre entidades de Derecho público y entidades del sector público.

(3) El artículo 55 del TRLEBEP no se limita a regular el acceso a la función pública, sino que se refiere al acceso al empleo público, que es un concepto más amplio.

(4) El artículo 55 del TRLEBEP se aplica a las entidades de Derecho público, en virtud de lo establecido en el artículo 2 de la misma norma. Así, con carácter general, el TRLEBEP no es aplicable a las entidades del sector público estatal que no se mencionan expresamente en el artículo 2. Sin embargo, conforme a la Disposición Adicional primera del TRLEBEP, el referido artículo 55 sí resulta de aplicación a las sociedades mercantiles públicas cuando su normativa específica las encuadre en el sector público estatal.

(5) El artículo 2 de la Ley 47/2003, de 26 de noviembre, General Presupuestaria ${ }^{8}$, tras establecer que forman parte del sector público estatal la Administración General del Estado y el sector público institucional estatal, concreta que en este último se integran las sociedades mercantiles estatales.

(6) De acuerdo con la derogada Disposición Adicional 12a de la LOFAGE, las sociedades mercantiles estatales no se rigen por el ordenamiento jurídico privado en materia de contratación.

(7) La LRJSP, aunque no resulte de aplicación por razones temporales, se considera ilustrativa, en la medida en que la misma se aplica al sector público institucional (cfr. artículo 2), y, por tanto, también a las sociedades mercantiles estatales. En ese sentido, se establece que estas sociedades deben regirse por lo previsto en la LPAP, y por el ordenamiento jurídico privado, salvo, entre otras, en materia de contratación (cfr. artículo 113). En

${ }^{8}$ BOE de 27 de noviembre de 2003, no. 284. 
concreto, en lo que respecta al personal de estas sociedades, debe estarse al Derecho laboral, así como a las normas aplicables en función de su adscripción al sector público estatal (cfr. artículo 117.4).

(8) La Ley 3/2017, de 27 de junio, de Presupuestos Generales del Estado para 2017, también encuadra en el sector público estatal a las sociedades mercantiles públicas, en los términos del artículo 111.1 de la LRJSP.

(9) El I Convenio colectivo del Grupo de empresas AENA acuerda en sus artículos 23.3, 24.2 (sic.) y 26.1 que el ingreso en las empresas de dicho grupo respetará los principios de igualdad, mérito, capacidad y publicidad.

(10) En lo que atañe a la propia jurisprudencia del TS acerca de la controversia litigiosa no ha habido pronunciamientos uniformes.

En efecto, conforme a la jurisprudencia, inicialmente se aplicó la condición de trabajador indefinido no fijo a Correos y Telégrafos SAE. Para ello se argumentó que, pese a su condición jurídica de S.A., se trataba de una entidad que pertenecía al sector público estatal, por lo que se regían para la contratación de sus trabajadores por el régimen de contratación de los entes púbicos recogidos en los artículos 23 y 103 de la Constitución, es decir, por los criterios de igualdad, mérito y capacidad acreditados en un proceso público de selección de los legalmente establecidos [SSTS de 22 de febrero de 2007 (Ro. 3353/2005, Sala de lo Social); de 28 de marzo de 2007 (Ro. 5082/2005, Sala de lo Social); de 26 de abril de 2007 (Ro. 229/2006, Sala de los Social); y de 6 de octubre de 2008 (Ro. 3064/2007, Sala de lo Social)].

Otro tanto sucedió para con Televisión Española S.A. o Radio Nacional de España S.A. [SSTS de 24 de julio de 2008 (Ro. 3964/2007, Sala de lo Social), de 9 de octubre de 2008 (Ro4029/2007, Sala de lo Social); de 12 de mayo de 2008 (Ro. 1956/2007, Sala de lo Social); de 3 de noviembre de 2008 (Ro. 4619/2006, Sala de lo Social); de 19 de enero de 2009 (Ro. 1066/2007, Sala de lo Social); y de 3 de abril de 2009 (Ro. 773/2007, Sala de lo Social), entre otras].

No obstante, posteriormente, la STS de 31 de marzo de 2015 (Ro. 102/2014, Sala de lo Social), en relación con la misma sociedad estatal AENA consideró lícita la preferencia en la permanencia reconocida a los trabajadores fijos en caso de movilidad geográfica. Para ello se argumentó que se trata del "específico supuesto del personal laboral que presta servicios en el sector público, en donde la categoría del trabajador fijo presenta un matiz adicional relacionado con el proceso de acceso al empleo y con la vinculación a un determinado puesto que trabajo, que excede de la figura del trabajador con contrato indefinido".

Del mismo modo, se llegó a la conclusión favorable a la acogida de la figura del personal laboral indefinido no fijo en el marco de la empresa pública en el supuesto de Eusko Irratia S.A, en la STS de 23 de noviembre de 2016 (Ro. 91/2016, Sala de lo Social). Al tratarse de una entidad que forma parte del sector público, y establecer su norma rectora, a saber, la Ley 5/1982, de 10 de mayo ${ }^{9}$ (cfr. artículo 47.1) que "la selección del personal para el Ente y sus Sociedades se hará mediante convocatoria pública y de acuerdo, con sistemas basados en los principios de mérito y capacidad", el TS aplicó los artículos 2, 55 y la Disposición Adicional primera del TRLEBEP.

En cambio, la STS de 18 de septiembre de 2014 (Ro. 2320/2013, Sala de lo Social) volvió a defender la condición de trabajador fijo respecto al personal laboral de la sociedad mercantil AENA, al considerar que el mismo queda fuera del ámbito de aplicación del TRLEBEP. Concretamente, se entiende que la justificación de la figura del trabajador indefinido no fijo se halla "en la necesidad de preservar los principios que rigen el acceso al ejercicio de una función pública;

${ }^{9}$ BOPV de 2 de junio de 1982, no. 71. 
elemento justificativo que desaparece por completo en el ámbito de las relaciones entre privados". A la misma conclusión llegó la STS también de 18 de septiembre de 2014 (Ro. 2323/2013, Sala de lo Social).

En relación con la empresa TRAGSA, la STS de 20 de octubre de 2015 (Ro. 172/2014, Sala de lo Social) señaló que las sociedades mercantiles estatales aunque forman parte del sector público empresarial estatal no son Administraciones públicas, de manera que "se regirán íntegramente, cualquiera que sea su forma jurídica, por el ordenamiento jurídico privado, salvo en las materias en que les sea de aplicación la normativa presupuestaria, contable, patrimonial, de control financiero y de contratación”. Pero, poco después, la STS de 6 de julio de 2016 (Ro. 229/2015, Sala de lo Social) matizó que TRAGSA es una sociedad mercantil estatal, no una entidad pública empresarial, y que la contratación que ha de sujetarse a las normas propias del sector público no es la de personal asalariado sino la de obras o servicios". De ahí que concluyera que las normas del TRLEBEP no son aplicables a las sociedades mercantiles de titularidad pública, por lo que no cabe extender a TRAGSA las normas sobre empleados públicos, y afirmara que "la construcción del indefinido no fijo es inaplicable a las sociedades anónimas, aunque pertenezcan al sector público, pues no están obligadas a cumplir con esos principios constitucionales del acceso "a la función pública", que es a lo que se contrae el mandato del artículo 103.3 de la Constitución”.

Igualmente, respecto a AENA S.A. los autos del TS de 22 de marzo de 2018 (Ro. 3014/2017, Sala de los Social); de 10 de abril de 2019 (Ro. 3661/2017, Sala de lo Social); de 19 de abril de 2018 (Ro. 2241/2017, Sala de lo Social); de 5 de septiembre de 2019 (Ro. 4531/2018, Sala de lo Social), entre otros, han inadmitido recursos de casación unificadora en los que se postulaba el acceso a la condición de indefinido no fijo de plantilla por fraude de ley en la contratación temporal en el ámbito de las sociedades estatales como AENA S.A. En concreto, se argumenta la falta de contenido casacional de dicha pretensión invocando la doctrina establecida en las dos sentencias del TS de 18 de septiembre de 2014 anteriormente mencionadas. En efecto, conforme a dicha doctrina "la figura del indefinido no fijo no es aplicable a AENA, aunque pertenezca al sector público, porque se trata de una sociedad mercantil estatal cuyo personal laboral está excluido de la aplicación del TRLEBEP”. Otro tanto sucede en los Autos del TS de 19 de julio de 2018 (Ro. 234/2018, Sala de lo Social); y de 26 de junio de 2018 (Rº. 90/2018, Sala de lo Social).

Por su parte, la STC 8/2015, de 22 de enero, reitera que "las "sociedades mercantiles estatales", aunque forman parte del sector público empresarial estatal, no son Administraciones públicas (artículo 2.2 LRJAP), de manera que "se regirán íntegramente, cualquiera que sea su forma jurídica, por el ordenamiento jurídico privado, salvo en las materias en que les sea de aplicación la normativa presupuestaria, contable, patrimonial, de control financiero y de contratación"”.

Una vez analizados todos estos aspectos desde la perspectiva tanto legislativa como jurisprudencial, y de establecer las conclusiones pertinentes, en el F.D. 9º el TS afirma que "una posterior reflexión nos ha llevado a concluir con carácter general que la condición de trabajador indefinido no fijo sí que es aplicable a las sociedades mercantiles estatales". Para ello se considera que el contrato indefinido no fijo no se aplica exclusivamente a las Administraciones públicas ni a las entidades de Derecho público, sino que también opera en las entidades del sector público en las que el acceso se rige por los principios de igualdad, mérito y capacidad, de conformidad con lo dispuesto en la Disposición Adicional primera, en relación con el artículo 55.1 y el 2 del TRLEBEP. En ese sentido, se señala que en virtud de dichos preceptos se amplía el ámbito de aplicación de tales principios consagrados en el artículo 103 de la Constitución, "a fin de evitar que la contratación temporal irregular permita el acceso a la condición de trabajador fijo de estas empresas del sector público. Se trata de salvaguardar el derecho de los ciudadanos a poder acceder en condiciones de igualdad al empleo público de dichas entidades". 
De ahí que se seńale por el TS que:

"La relación laboral indefinida no fija tiene como finalidad salvaguardar los principios que deben observarse en el acceso al empleo público (no solo a la función pública) a fin de evitar que el personal laboral temporal contratado irregularmente por una entidad del sector público adquiera la condición de trabajador fijo en el puesto que venía desempeñando. Para impedirlo, su condición pasa a ser la de trabajador contratado por tiempo indefinido con derecho a ocupar la plaza hasta que se cubra por el procedimiento previsto o se amortice. Dicha finalidad debe cumplirse también en las entidades públicas cuya normativa prevé el acceso respetando los criterios de igualdad, mérito y capacidad".

Finalmente, en el F.D. $10^{\circ}$, el TS resuelve la cuestión litigiosa, estimando el recurso interpuesto por AENA S.A., y, en consecuencia, casando y anulando la sentencia recurrida y resolviendo el debate planteado en el sentido de declarar que la relación laboral, que une a las partes, es indefinida no fija.

\section{Voto particular}

La STS objeto de estudio cuenta con un Voto Particular, a saber, el formulado por el Magistrado Antonio V. Sempere Navarro, que aboga por que el recurso interpuesto por AENA S.A. debiera haberse desestimado.

El principal argumento esgrimido para ello es que "una entidad pública empresarial posee ontología de Derecho público (artículo 103.1 LRSJP) y una sociedad mercantil, aunque se integre en el sector público, posee naturaleza de Derecho privado".

Entiende Sempere Navarro que la extensión realizada por ley y al margen de la Constitución de los principios de igualdad, mérito y capacidad a una sociedad mercantil de titularidad pública conlleva la aplicación de consecuencias distintas cuando se vulneran tales principios.

Precisamente, a su entender, en ello descansa la figura del indefinido no fijo, de forma y manera que tan solo procede la misma cuando el bloque normativo que exige la observancia de los principios de igualdad, mérito y capacidad está integrado por preceptos constitucionales (v.gr. artículos 23 y 103 de la Constitución). Por el contrario, cuando el bloque normativo que conlleva la aplicación de tales principios encuentra su amparo en preceptos de rango legal no procede la aplicación de la figura de indefinido no fijo.

Por consiguiente, deduce Sempere Navarro que la extensión de la figura del indefinido no fijo a las sociedades mercantiles públicas supone postergar las consecuencias comunes incorporadas al Real Decreto Legislativo 2/2015, de 23 de octubre, por el que se aprueba el texto refundido de la Ley del Estatuto de los Trabajadores (TRLET) ${ }^{10}$, lo que acaba por afectar al derecho al trabajo (artículo 35 de la Constitución), a la virtualidad del TRLET (artículo 35.2 de la Constitución) y a las exigencias de no discriminación (artículo 14 de la Constitución). La consecuencia es clara para el magistrado discrepante con la resolución adoptada: "La extensión del ámbito subjetivo de la figura del "indefinido no fijo" se hace en perjuicio de quienes trabajan y (...) sin resortes que así lo justifiquen”. Ciertamente, la no aplicación de las normas laborales comunes se realiza, a su entender, "sin una exigencia constitucional o un claro mandato legislativo". En esa línea, incluso va más allá, al afirmar que, aunque se llegara a la conclusión de que el TRLEBEP y normas concordantes resultaran de aplicación a las sociedades mercantiles de titularidad mayoritariamente pública, y, por tanto, también los principios referidos, la infracción de dichos principios no impediría la conver-

${ }^{10}$ BOE de 24 de octubre de 2015, no. 255. 
sión en fijos de los trabajadores afectados, al faltar "la palanca supralegal que lo justifique". Es más, deja entrever, aunque de una manera no suficientemente clara, que incluso antes de apostar por la extensión de la figura del indefinido no fijo a las sociedades mercantiles públicas cabrían otras soluciones, entre las que destaca las siguientes: "sanción a la empresa, responsabilidad de las personas responsables, solicitud de anulación del contrato (...)". Lamentablemente, no profundiza en las mismas, y se limita a señalar que "no corresponde a este Voto Particular exponer" tales resortes que el ordenamiento jurídico contempla para dicha situación.

Además del principal argumento que se acaba de exponer, el Voto Particular contiene otros argumentos que, aunque puedan ser considerados menores, apuntan en la misma dirección.

Así, a la luz de las SSTS de 20 de octubre de 2015 (Ro. 172/2014, Sala de los Social) y de 6 de julio de 2016 (Ro. 229/2015, Sala de lo Social), ambas sobre la empresa TRAGSA, en primer lugar, se concluye que las entidades públicas empresariales y las sociedades mercantiles estatales, aunque ambas se integren en el sector público, no son equiparables a los efectos de aplicar el TRLEBEP, dado que esta última norma tan solo se referiría las primeras. Esta afirmación se completa, asimismo, con la STC 8/2015, de 22 de enero, que diferencia dentro del sector público empresarial las entidades púbicas empresariales y las sociedades mercantiles estatales. En segundo lugar, también se concluye que la "contratación" que ha de sujetarse a normas propias del sector público a la luz de la normativa analizada en la sentencia objeto de estudio no es la del personal asalariado sino la que corresponda a la de obras o servicios.

\section{Valoración personal}

La valoración que merece la sentencia objeto de estudio debe partir del hecho indiscutible de que a las sociedades mercantiles públicas se les deben aplicar los principios de igualdad, mérito y capacidad, no solo porque así se establezca en el correspondiente Convenio colectivo que resulte de aplicación, como sucede en el caso de AENA S.A., sino que también porque, como hace ya un tiempo parte de la doctrina científica advirtió, "las formas instrumentales adoptadas por la propia Administración no pueden permitirle eludir principios que desde la misma Constitución la vinculan" ${ }^{11}$. Ciertamente, lo contrario supondría, como también ha sabido advertir con rotundidad algún autor, crear un campo abonado para la proliferación de las corruptelas y accesos laborales bajo criterios "digitales", "de hecho", o de "clientelismo", y que al amparo de la denominada "huida del Derecho Administrativo" al crear empresas públicas se convierte en el instrumento adecuado para que al amparo de la doctrina de la Jurisdicción Social se evite la utilización de procesos selectivos legales y sometidos a las exigencias constitucionales ${ }^{12}$.

En ese sentido, llama la atención que ni la sentencia objeto de estudio ni el Voto Particular que la misma contiene se refieran a lo preceptuado por la Disposición Adicional 34a de la Ley 3/2017, de 27 de junio, de Presupuestos Generales del Estado para 2017.

\footnotetext{
${ }^{11}$ GONZÁLEZ BIEDMA, Eduardo y CALVO GALLEGO, Javier, Las relaciones de trabajo en las empresas públicas. Relaciones laborales, tomo 1, 1992, p. 7 (LA LEY 975/2001).

${ }^{12}$ FONDEVILA ANTOLÍN, Jorge, Algunas propuestas para una necesaria revisión de la cuestionable doctrina judicial del reconocimiento, al personal laboral temporal y funcionarios interinos, de la condición de "indefinidos no fijo". Gabilex: Revista del Gabinete Jurídico de Castilla-La Mancha, no 13, 2018, pp. 37-38. En parecidos términos, por referirse a entrar en la plantilla por la "puerta de atrás" y no utilizando la "puerta principal", BALLESTER PASTOR, Inmaculada, En torno a la contratación temporal fraudulenta en el ámbito de los Organismos Públicos: el caso particular de trabajadores de CORREOS y TELEGRAFOS S.A., tras perder este Organismo su carácter público. Comentario a las SSTSJ Cataluña 12, 26 y 27 de junio de 2003. Revista Doctrinal Aranzadi Social, no 5315, 2003 p. 3 (BIB 2003\1347).
} 
En efecto, dicha disposición, bajo la rúbrica "Exigencia de responsabilidades en las Administraciones Públicas y entidades dependientes de las mismas por la utilización de la contratación laboral”, en su apartado UNO establece que:

"Los contratos de trabajo de personal laboral en las Administraciones Públicas y en su sector público, cualquiera que sea la duración de los mismos, deberán formalizarse siguiendo las prescripciones y en los términos establecidos en el Estatuto de los Trabajadores y demás normativa reguladora de la contratación laboral, así como de acuerdo con las previsiones de la correspondiente Ley de Presupuestos Generales del Estado, siéndoles de aplicación los principios de igualdad, publicidad, mérito y capacidad en el acceso al empleo público (...)”.

De este modo, no discutiéndose que las sociedades mercantiles públicas pertenezcan al sector público, el mandato de esta disposición para con el respecto de los principios en cuestión es claro y no merece mayor comentario.

Es verdad que, como se ha señalado supra, en el Voto Particular se deja entrever que incluso antes de apostar por la extensión de la figura del indefinido no fijo a las sociedades mercantiles públicas cabrían otras soluciones, entre las que se destacan las siguientes: "sanción a la empresa, responsabilidad de las personas responsables, solicitud de anulación del contrato (...)”. Pero sorprendentemente, se entra en un debate estéril, en el sentido de que se rechaza la posibilidad de extender a las sociedades mercantiles públicas la figura del indefinido no fijo por considerar que esta solo procede en el ámbito de las entidades públicas empresariales que poseen ontología de Derecho público y no en las sociedades mercantiles que poseen naturaleza de Derecho privado.

Concretamente, se entiende que dicho debate es estéril porque el apartado DOS de la referida Disposición Adicional 34a de la Ley 3/2017 establece expresamente que:

"Los órganos competentes en materia de personal en cada una de las Administraciones Públicas y en las entidades que conforman su Sector Público Instrumental serán responsables del cumplimiento de la (...) [normativa citada en el apartado UNO], y en especial velarán para evitar cualquier tipo de irregularidad en la contratación laboral temporal que pueda dar lugar a la conversión de un contrato temporal en indefinido no fijo (...)".

Sin duda, las sociedades mercantiles forman parte del Sector Público Instrumental ${ }^{13}$, sin perjuicio de que se utilice la expresión "entidades", en sentido amplio, para referirse a una variada gama de realidades que cuentan con distintos regímenes jurídicos, como las propias sociedades mercantiles públicas, los organismos autónomos, las entidades de Derecho público, las fundaciones públicas o los consorcios públicos ${ }^{14}$.

Es más, el taxativo mandato de velar por evitar cualquier tipo de irregularidad en la contratación laboral temporal que pueda dar lugar a la conversión de un contrato temporal en indefinido no fijo demuestra que con mucha más razón deba desecharse la posibilidad de que tales irregularidades supongan la conversión de los trabajadores temporales en fijos. Al respecto debe considerarse que al contrario de lo que sucede cuando no operan los principios de igualdad, mérito y capacidad, aquí no cabe hablar de sanción para con la empresa, porque tanto la figura del indefinido no fijo

\footnotetext{
${ }^{13}$ Algunos autores han preferido hablar de "Entes Instrumentales" formados por Entidades Privadas del Sector Público, entre las que incluyen a las sociedades mercantiles del sector público (Por todos, véase DE NIEVES NIETO, Nuria, El acceso al empleo público. Revista del Ministerio de Trabajo e Inmigración, no 93, 2011, p. 51).

${ }^{14}$ Sobre las confusiones existentes en torno a estas entidades véase ROLDÁN MARTÍNEZ, Aránzazu, Transformación en indefinidos de los contratos de interinidad por vacante celebrados por la Sociedad Mercantil Estatal Correos y Telégrafos. Comentario a Sentencia de la AN de 10 de febrero de 2004. Revista Doctrinal Aranzadi Social, no 3, 2004, p. 18 (BIB 20041418).
} 
como la del fijo, ante contrataciones irregulares, suponen prolongar en el tiempo una situación que nunca debió producirse, al mantener contratada a una persona que no cumple con los principios mencionados; legalizan una contratación en origen fraudulenta; atentan contra el interés general; y no tienen en cuenta que habrá que echar mano de recursos públicos para hacer frente al pago de la indemnización correspondiente, en caso de amortización ${ }^{15}$.

En coherencia con ello, debe concluirse, además, que la transformación de los trabajadores temporales que han sido contratados de manera abusiva en el marco de una concatenación o sucesión de contratos en indefinidos no fijos, como sucede con las dos trabajadoras de la sentencia objeto de estudio, se opone a la jurisprudencia sentada por la STJUE de 19 de marzo de 2020 (asuntos acumulados C-103/18 y C-429/18, Domingo Sánchez Ruiz y otros). Así, por las razones antedichas, y a la luz de dicha sentencia, la transformación en indefinidos no fijos no sería una medida adecuada para prevenir y sancionar la temporalidad en las sociedades mercantiles públicas, en los términos de la Cláusula 5 del Acuerdo Marco sobre el trabajo con contrato de duración determinada anexado a la Directiva 1999/70/CE del Consejo, de 28 de junio ${ }^{16}{ }^{17}$. Ciertamente, conforme a lo establecido por la STJUE de 19 de marzo de 2020, mutatis mutandis, la transformación de las dos trabajadoras temporales en la sentencia objeto de comentario en este estudio en indefinidas no fijas no permite por sí sola alcanzar la finalidad perseguida por la Cláusula 5 del Acuerdo Marco, pues dicha transformación se produce sin perjuicio de la posibilidad de que AENA S.A. amortice las plazas o cese a las dos trabajadoras cuando las plazas se cubran por reingreso de trabajadores que accedan a tales puestos conforme a los principios constitucionales de igualdad, mérito y capacidad.

Por el contrario, la medida efectiva para prevenir y sancionar dicha temporalidad fraudulenta, en sintonía con lo establecido en el apartado TRES de la Disposición Adicional $34^{a}$ de la Ley 3/2017, consistiría en la exigencia de responsabilidades a los órganos de contratación de las sociedades mercantiles públicas. De ese modo, si bien inicialmente la sociedad mercantil debiera responder, abonando la indemnización correspondiente al trabajador contratado irregularmente, que, por analogía con lo que se viene abonando a los indefinidos no fijos cuando se procede a la amortización de sus puestos de trabajo, equivaldría a la cuantía correspondiente a los despidos objetivos ${ }^{18}$, posteriormente cabría repetir contra los responsables de la contratación, sin perjuicio de las responsabilidades penales en las que estos también pudieran haber incurrido. Se entiende que procedería una aplicación analógica con respecto a los supuestos de amortización de puestos de trabajo porque se considera que las contrataciones serían nulas con efectos ex nunc como consecuencia de las modulaciones que en los contratos de trabajo procede realizar en virtud de lo dispuesto en el artículo 9 del TRLET ${ }^{19}$.

Por todo ello, dado que, como se acaba de señalar, existen medidas alternativas y eficaces para evitar que personas que no cumplen con los principios de igualdad, mérito y capacidad sigan trabajando en sociedades mercantiles públicas, debe concluirse que no es justificada la extensión de la figura del indefinido no fijo a los trabajadores de dichas sociedades. Lo contrario significa simple y llanamente perpetuar una situación ilegal.

\footnotetext{
${ }^{15}$ En esa línea, véase ARUFE VARELA, Alberto, Los trabajadores indefinidos no fijos al servicio de las Administraciones públicas: una anomalía jurisprudencial y legal. Revista General de Derecho del Trabajo y de la Seguridad Social, no 40, 2015, p. 104.

${ }^{16}$ DOCE de 10 de julio de 1999, L 175.

${ }^{17} \mathrm{Al}$ respecto, véase ARRIETA IDIAKEZ, Francisco Javier, El empleo temporal en las Administraciones públicas: límites, prevención y sanción a su utilización. Lan Harremanak: Revista de Relaciones Laborales, 42, 2020, pp. 22 y 26.

${ }^{18}$ Así es a partir de la STS de 24 de junio de 2014 (Ro. 217/2013, Sala de lo Social).

${ }^{19}$ Vid. MORENO BRENES, Pedro, Irregularidades en la selección de personal laboral: algunas formas de reacción jurídica en las AA.PP. y en las sociedades públicas. El Consultor de los Ayuntamientos y de los Juzgados. Revista técnica especializada en Administración local y justicia municipal, tomo 3, 2006, p. 6 (LA LEY 3646/2006).
} 